\title{
Caribou Management in Greenland
}

\author{
Nuka Møller Lund
}

Ministry of Fisheries and Hunting, Greenland

Copyright $\mathrm{C} 2016$ by authors, all rights reserved. Authors agree that this article remains permanently open access under the terms of the Creative Commons Attribution License 4.0 International License

\begin{abstract}
Caribous in Greenland have been hunted ever since the ancient hunters were hunting with bow and arrow and still today the caribou is one of the most important animals being hunted in Greenland for both professional hunters and leisure-hunters. Today the hunting-pressure is much higher than back in those ancient days and the weapons and boats are much more effective, so therefore Caribou management based on the principle of sustainability and conservation of the caribou is essential. Hunting-periods and quotas for professional hunters and leisure-hunters are decided in the Ministry of Fisheries and Hunting on a yearly basis while hunting-periods for trophy-hunting on muskoxen and caribou are decided every three years. Biological advice based on surveys and minimum-counts have been basis for the decisions for many years, but in recent years decisions have been made to a certain degree on the precautionary principle due to the lack of new surveys.
\end{abstract}

Keywords Caribou Management, Traditional Hunting, Harvesting Statistics and Future Management

\section{Introduction}

Greenland is big, but most of it however is covered by the Icecap, that everybody seems to be talking about these days, whenever global warming and melting ice due to too much $\mathrm{CO}_{2}$-emission from industries and traffic around the globe is being mentioned - whatever consequences that might have for certain parts of the rest of the world.

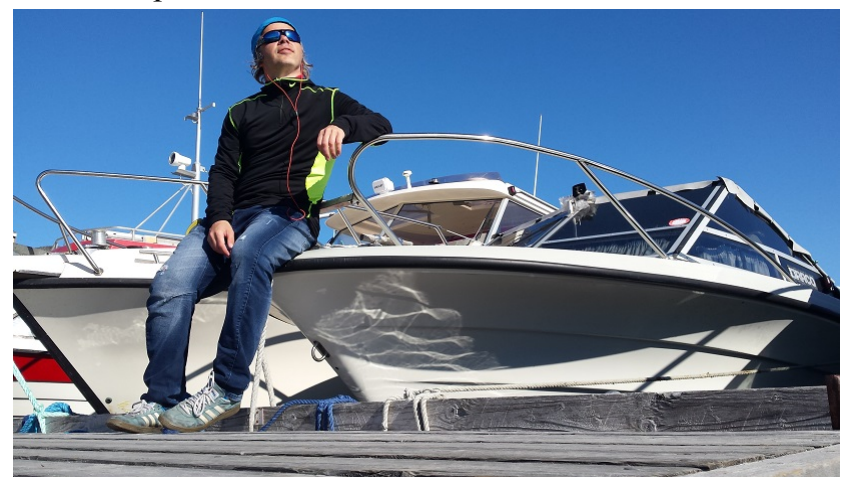

Head of Section Nuka Møller Lund from Ministry of Fisheries and Hunting in Greenland
The land along the edge of the Icecap is rich on living natural resources such as caribous, muskoxen and other smaller species such as foxes, ptarmigans, polar-hares and salmon. The professional hunters and leisure-hunters in Greenland depend more or less on hunting these animals now and in the future - and therefore it is important that the management is based on the principle of sustainability with conservation of the caribou in Greenland in mind.

\section{Caribou-regions in Greenland}

Caribous in Greenland are concentrated on the Westcoast of Greenland and have been of great use to the ancient hunters from way back in time, when they hunted traditionally using bow and arrow. Still today the caribou is the main topic among people on the street, whenever the hunting-season begins. During hunting-season the caribous are being hunted by professional hunters, leisure-hunters and also to a lesser degree by trophy-hunters coming to Greenland from around the world. There are 11 hunting-regions on the Westcoast of Greenland with a total number of more than 100.000 caribous.

The biggest stock of caribous is on the southern part of the Westcoast where the biggest areas of land uncovered by ice are located. This area is called Sisimiut-Kangerlussuaq Sisimiut being the second biggest town in Greenland and Kangerlussuaq being the biggest settlement in the Qeqqata Municipality. The 2016 hunting-period for leisure-hunters in this region runs from 1st of August until 30th of September with open quota and for professional hunters it runs a little longer until 15 th of October also with open quota. In this particular hunting-region - Sisimiut-Kangerlussuaq - there is also a short hunting-period for professional hunters during the winter 2017 with open quota and this is due to the high number of caribou - which in 2010 was approx. 58.000 [1] and the only aim is to bring down the number of caribou to reduce the risk of overgrazing and later collapse of the population in the high-density areas of the region. The hunting-period during winter 2017 runs from 18th of February until 10th of March - thus running for three weeks. Sisimiut-Kangerlussuaq is the only caribou-region in Greenland with this kind of problem and it is probably due to low accessibility of most of the land.

The Akia-Maniitsoq stock of caribou is located just south 
of the Sisimiut-Kangerlussuaq-area and the number of caribous here is approx. 24.000 according to a survey from 2012 [2]. The hunting-periods in this region during the autumn for professional hunters and leisure-hunters accordingly are the same as the hunting-periods for the Sisimiut-Kangerlussuaq-area mentioned above. There is no hunting-period during the winter 2017 in Akia-Maniitsoq, because there is no need to further reduce the number of caribous in this region.

Further south and also south of Nuuk - the capitol of Greenland - the Ameralik-region is located. According to a survey from 2012[1], the number of caribous in this region is approx. 12.000 with a high percentage of calves per 100 cows, which means that the number of caribous potentially can rise pretty quickly. Hunting periods for the Ameralik-region during autumn 2016 are the same as for the two regions mentioned beforehand and again there is no hunting-period during winter 2017, because there is no need to further reduce the number of caribous in the Ameralik-region.

The last of the four biggest caribou-regions on the Westcoast of Greenland is the Qeqertarsuatsiaat-region with approx. 5.000 caribous according to a survey from 2012 [2]. Qeqertarsuatsiaat is also the name of a settlement with 200-300 inhabitants approx. 80 miles south of Nuuk. According to the professional hunters from Nuuk some of the caribous from the Ameralik-region seem to be migrating south towards the Qeqertarsuatsiaat-region.

The rest of the Caribou-stocks on the Westcoast of Greenland are smaller stocks with numbers varying from approx. 100 caribous to approx. 3.000 caribous. Apart from the professional hunters, leisure-hunters and trophy-hunters there are not many predators in Greenland. However a few wolves have found their way to Greenland seemingly coming from Nunavut by crossing the sea-ice eastbound to Greenland. There have been some encounters between humans and wolves during the last few years - mainly in the Qaanaaq-region and further up north-east, but also as far south as the Upernavik-region. Until now the wolves have not been a problem for the caribous.

\section{Caribou Management in Greenland}

Caribou-management in Greenland is based on sustainability and therefore also conserving the caribou. Sustainability means that you cannot catch too many, because you have to think of the future and the coming years as well - and that is exactly the link between sustainability and conservation. Allowing hunting to a certain degree is to reduce the risk of overgrazing and in time a possible collapse of a population. As mentioned before only one of the biggest caribou-populations in Greenland needs to be strongly reduced in numbers according to the latest surveys from 2010 and 2012. The rest of them are more or less stable in numbers after having been reduced by means of winter-hunting during a 10-year period. For instance in
Akia-Maniitsoq the population was at 46.000 [3] in 2001 while the Ameralik-population was at 32.000 [3] that same year.

Hunting-periods and quotas for professional hunting and leisure-hunting are managed on a yearly basis according to the Government of Greenland Executive Order number 7 of June 27th 2013. The Minister of Hunting makes the decisions around mid-June each year based on biological advice provided by the Greenland Institute of Natural Resources followed by public hearing of The Hunting Council, The Organization of Hunters in Greenland, The Organization of Municipalities in Greenland and others such as leisure-hunters and organizers of trophy-hunting. Hunting-periods and quotas for trophy-hunting on caribous and muskoxen are decided every three years, because the organizers need to know the hunting-periods and quotas for the coming years due to planning.

During this process the communities divide quotas for professional hunting and leisure-hunting within the community and in some regions also decide hunting-periods within the period from 1st of August to 30th of April the following year.

\subsection{Protective Elements in the Greenland Government Executive Order}

There are protective elements in the Executive Order mentioned previously. First of all the hunting-periods are limited in time - for instance from the 1st of August until 15th of October in most regions - and therefore no hunt on the caribous are allowed for the rest of the year. Furthermore hunting-periods cannot be decided within the period from 1 st of May until 31st of July and therefore no hunt on the caribous is allowed during the calving-season.

Professional hunters and leisure-hunters with a hunting-license and a license specifically to hunt caribous are allowed to do so. The hunting-licenses for professional hunters and leisure-hunters are renewed every year around mid-October, after the hunters have reported the year's catch to the Ministry of Fisheries and Hunting. Licenses to hunt caribous are distributed from the communities to the hunters.

Motorized vehicles such as ATV's and Snowmobiles are not allowed during the hunt and they have to keep a distance of at least 500 meters to caribous and muskoxen. This is according to the Executive Orders, but some municipalities such as Qeqqata Municipality have rules, that permit the use of ATV's and Snowmobiles during winter whenever the ground is frozen and therefore these vehicles are being used to transport the catch of both caribous and muskoxen. Especially the ATV's are being used to transport the catch from the hunting-ground to the slaughter-house during winter-hunt on muskoxen on the Southside of Kangerlussuaq in the Qeqqata Municipality. Some hunting-grounds are as far away as 50 miles from the slaughter-house and the ATV's usually transport 3-4 muskoxen at once pulling a sledge behind the ATV.

Further protective elements in the Executive Order on 
Caribous to mention are no dogs allowed during the hunting and the use of certain minimum-calibers. For professional hunters and leisure-hunters the minimum caliber is .222 and for trophy-hunters it is .243. This is to secure that the caribou is being killed fast and efficiently during the hunt. Also the hunters are responsible for the weapon being accurate as well as being well taken care of and with the hunting-culture of Greenland in mind this does not seem to be a problem.

According to the Executive Order from 2013 the use of Bow and Arrow is allowed when hunting caribou in Greenland - however as for now only the Compound-bow is allowed here in Greenland. Minimum pulling force has to be 45 pounds when using fixed arrow-heads and 55 pounds when using mechanical arrow-heads. Furthermore fixed arrow-heads have to weigh minimum 385 grains and mechanical arrow-heads have to weigh 425 grains. Only bow-hunters with a certificate are allowed to hunt using bow and arrow.

\subsection{Harvest-numbers on Caribou in Greenland during the Years 2010-2014}

The number of caribous being caught by each hunter professional hunters and leisure-hunters separately - are being reported to The Ministry of Hunting around mid-October each year. Here the harvest-numbers are being entered into a harvest-system, so it is possible for us to get harvest-numbers for each community, each year as well as professional hunters and leisure-hunters separately. The harvest-numbers for the five management-areas with the highest harvest-numbers in Greenland in the years 2010-2014 are as follows.

The management-areas each represent the city mentioned and the settlements within the area. However the harvest-numbers do not reflect where the catch was made, so in some cases it could be catch from another management-area, which is possible when there is an open quota in the actual management-area.

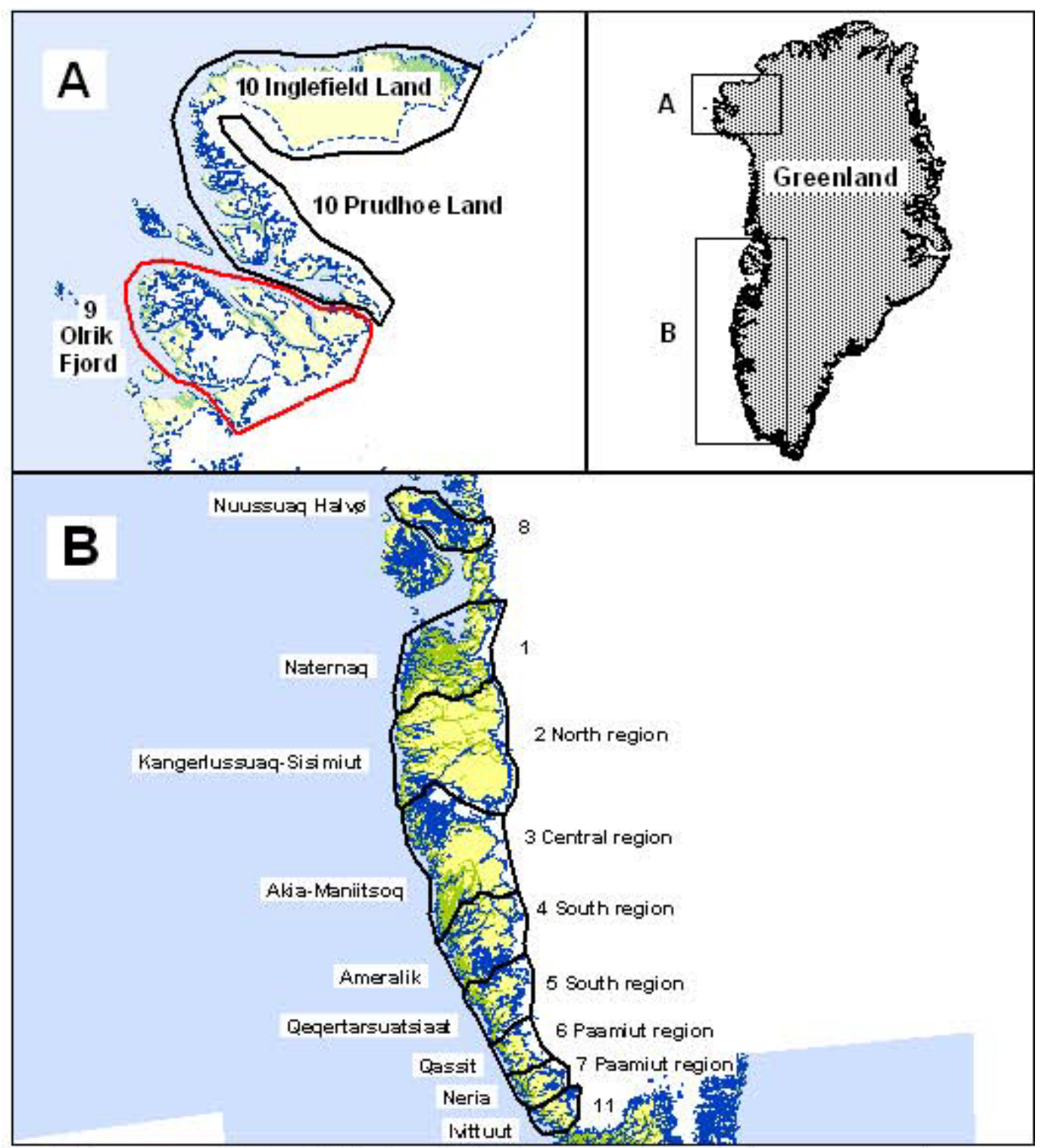

Figure 1. The Caribou-regions on the Westcoast of Greenland 


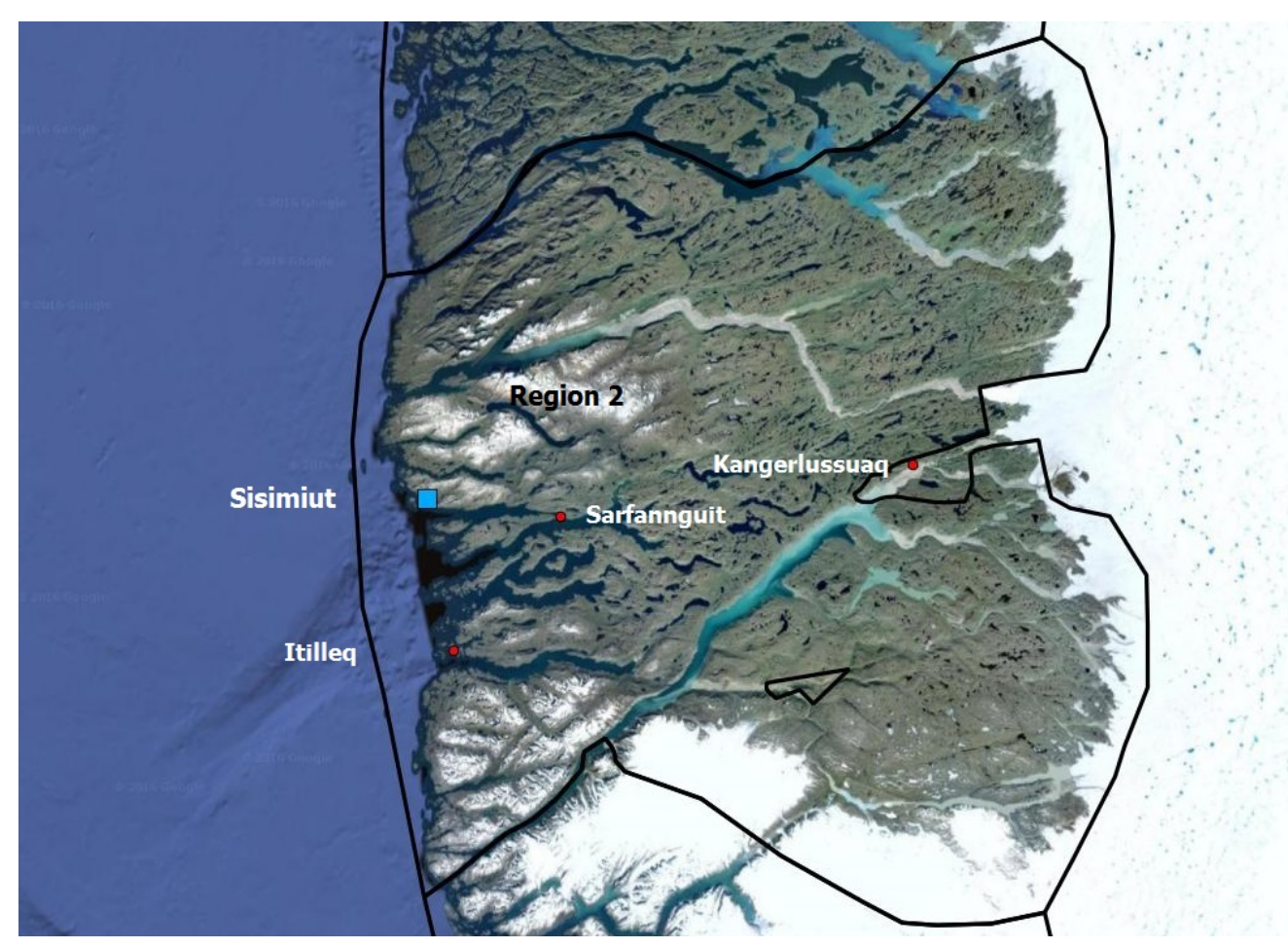

Figure 2. The approx. $26.000 \mathrm{~km}^{2}$ Sisimiut-Kangerlussuaq Caribou-region also called Region 2.

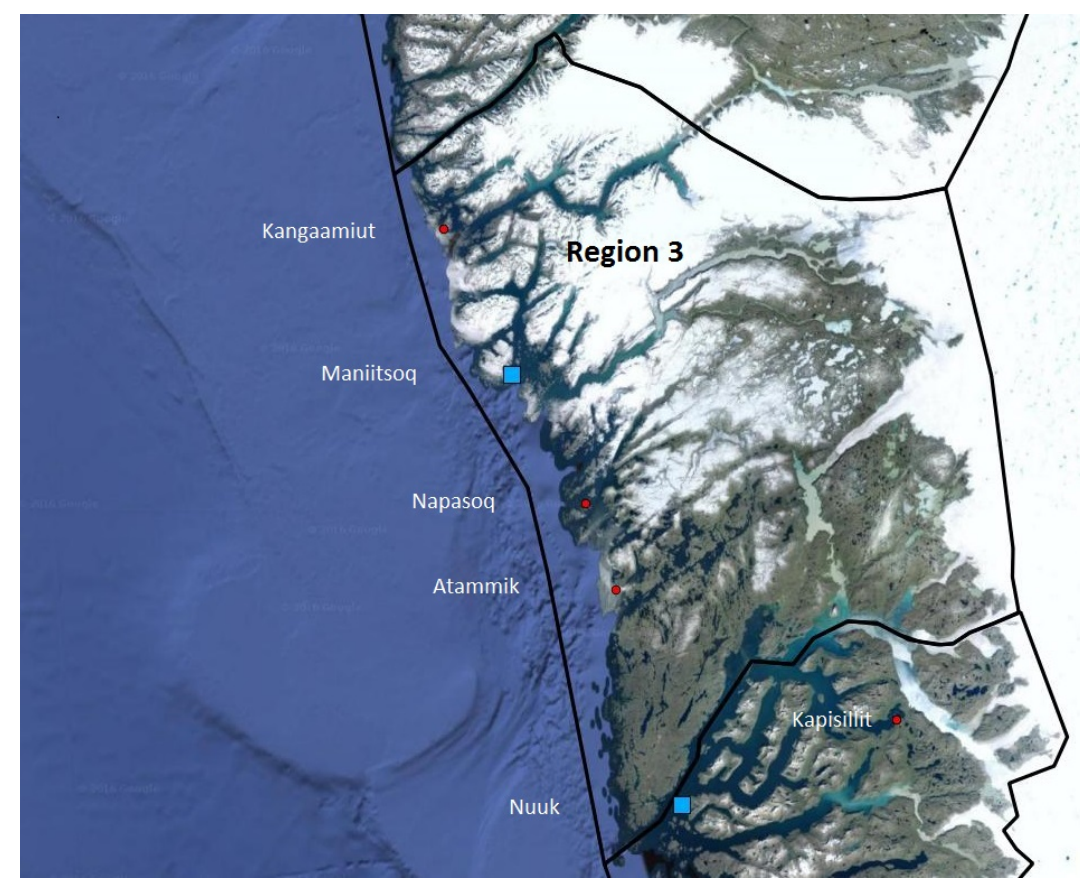

Figure 3. The approx.. $15.000 \mathrm{~km}^{2}$ Akia-Maniitsoq Caribou-region also called Region 3. 


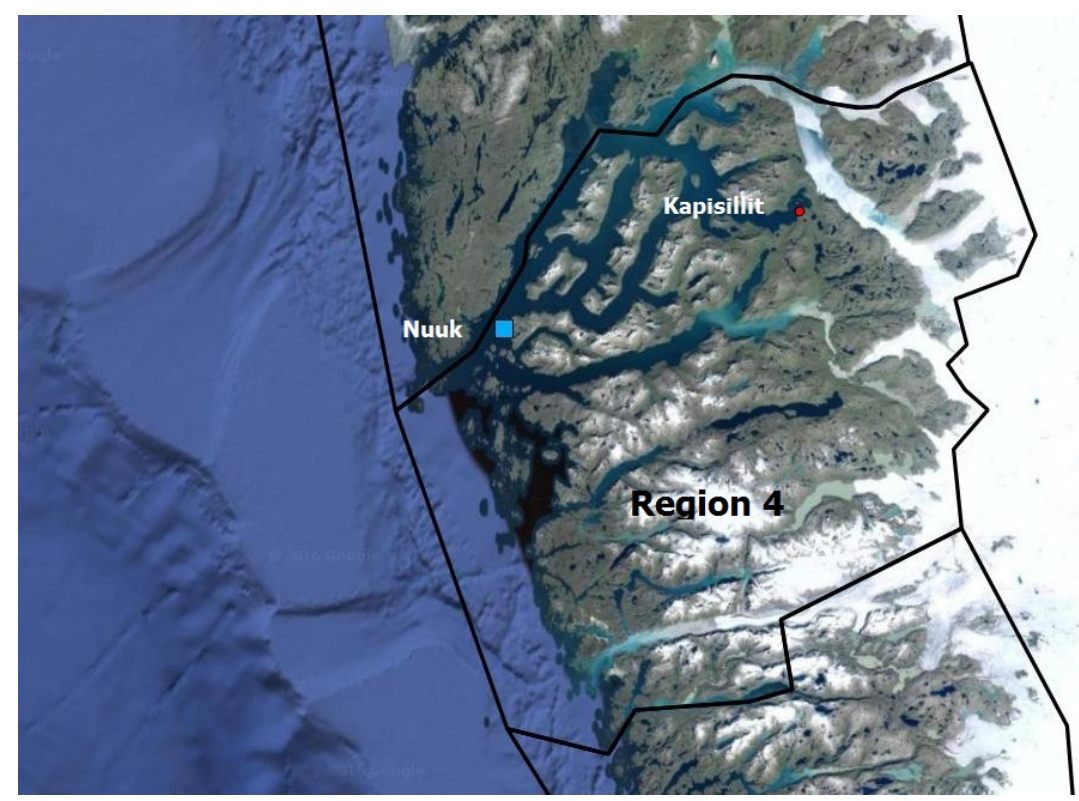

Figure 4. The approx.. $8.000 \mathrm{~km}^{2}$ Ameralik Caribou-region also called Region 4.

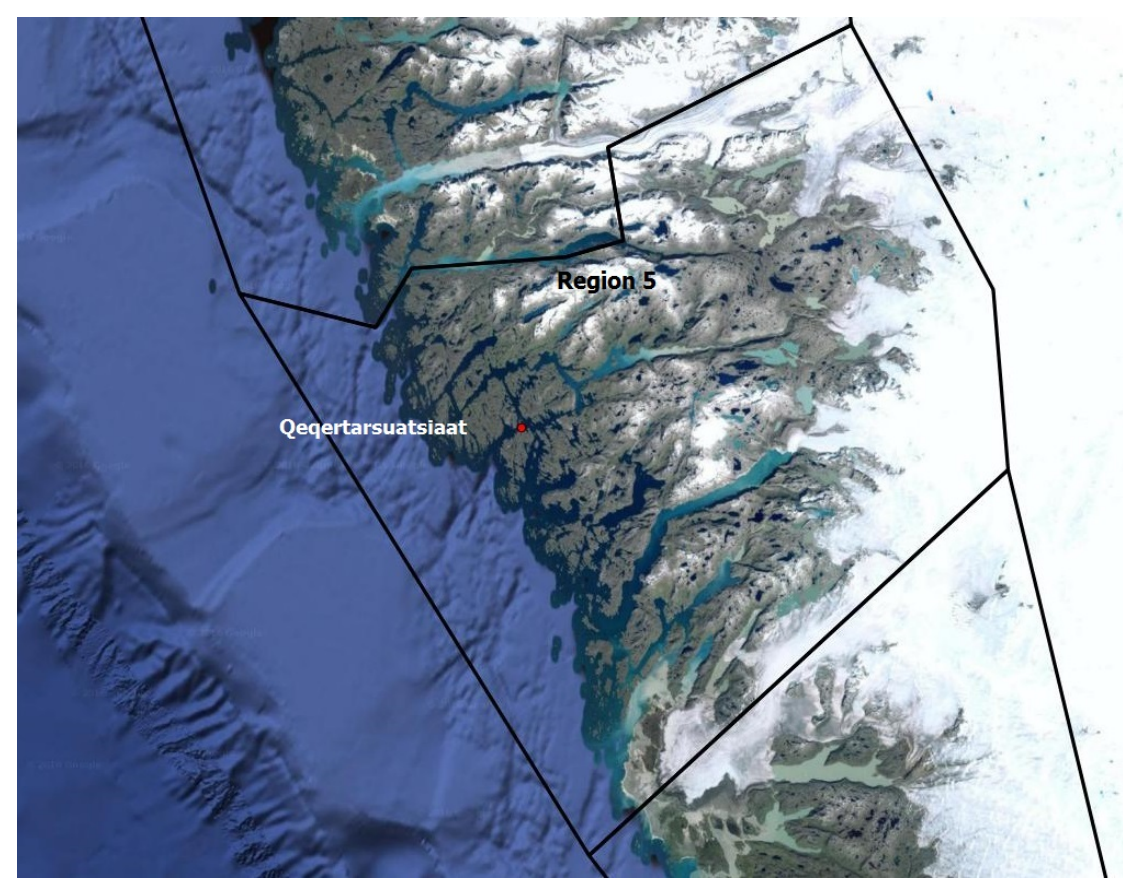

Figure 5. The approx. $5.000 \mathrm{~km}^{2}$ Qeqertarsuatsiaat Caribou-region also called Region 5 . 


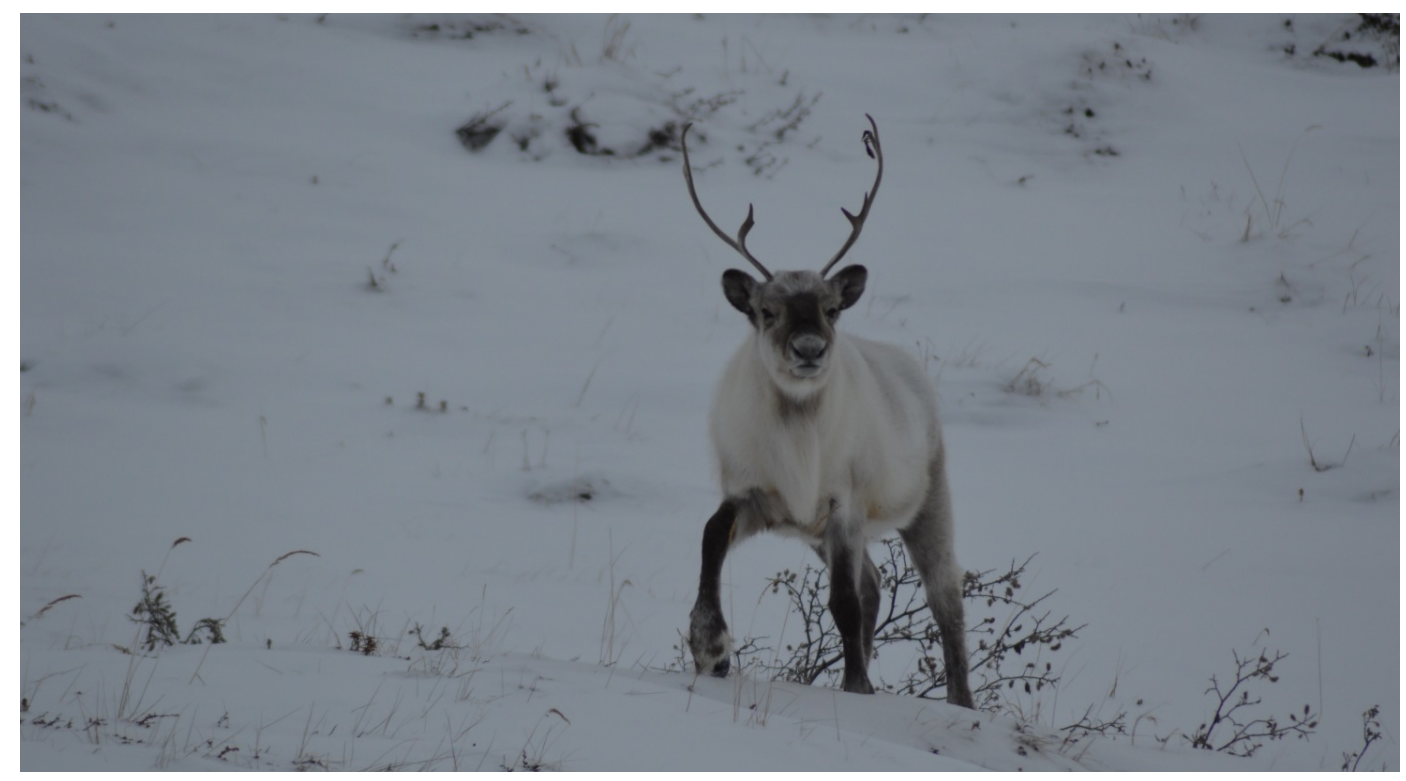

Figure 6. Caribou-cow photographed on October $24^{\text {th }} 2016$ in Kangerlussuaq

Table 1. Statistics on harvest-numbers on Caribou, the numbers of professional hunters and the average number of Caribous being caught per professional hunter during the years 2010-2014.

\begin{tabular}{|c|c|c|c|c|c|}
\hline Year/Community & Nuuk & Sisimiut & Maniitsoq & Kangaatsiaq & Ilulissat \\
\hline 2010 & $2324 / 112 / 20,8$ & $1886 / 127 / 14,9$ & $1214 / 166 / 7,3$ & $1144 / 95 / 12,0$ & $426 / 250 / 1,7$ \\
\hline 2011 & $2146 / 125 / 17,2$ & $1927 / 132 / 14,6$ & $1184 / 152 / 7,8$ & $1109 / 107 / 10,4$ & $391 / 252 / 1,6$ \\
\hline 2012 & $2105 / 106 / 19,9$ & $1551 / 112 / 13,8$ & $884 / 129 / 6,9$ & $934 / 95 / 9,8$ & $413 / 207 / 2,0$ \\
\hline 2013 & $1806 / 122 / 14,8$ & $1469 / 123 / 11,9$ & $919 / 152 / 6,0$ & $1057 / 97 / 10,9$ & $625 / 268 / 2,3$ \\
\hline 2014 & $1850 / 126 / 14,7$ & $1349 / 123 / 11,0$ & $1378 / 169 / 8,2$ & $997 / 106 / 9,4$ & $547 / 256 / 2,1$ \\
\hline
\end{tabular}

Table 2. Statistics on harvest-numbers on Caribou, the numbers of leisure-hunters and the average numbers of Caribous being caught per leisure-hunter during the years 2010-2014.

\begin{tabular}{|c|c|c|c|c|c|}
\hline Year/Community & Nuuk & Sisimiut & Maniitsoq & Kangaatsiaq & Ilulissat \\
\hline 2010 & $1271 / 1124 / 1,1$ & $970 / 648 / 1,5$ & $582 / 367 / 1,6$ & $183 / 94 / 1,8$ & $311 / 451 / 0,7$ \\
\hline 2011 & $1236 / 947 / 1,3$ & $904 / 570 / 1,6$ & $567 / 302 / 1,9$ & $130 / 81 / 1,6$ & $339 / 416 / 0,8$ \\
\hline 2012 & $1615 / 674 / 2,4$ & $1069 / 455 / 2,3$ & $490 / 239 / 2,1$ & $107 / 56 / 1,9$ & $239 / 300 / 0,8$ \\
\hline 2013 & $1574 / 678 / 2,3$ & $1030 / 503 / 2,0$ & $448 / 245 / 1,8$ & $111 / 64 / 1,7$ & $316 / 339 / 0,9$ \\
\hline 2014 & $2243 / 624 / 3,6$ & $1124 / 544 / 2,1$ & $508 / 238 / 2,1$ & $97 / 52 / 1,9$ & $283 / 314 / 0,9$ \\
\hline
\end{tabular}

Comparing the harvest-numbers to the number of professional hunters and leisure-hunters accordingly makes it possible to conclude something about the development in professional hunting on caribou and leisure-hunting on caribou accordingly.

In general the numbers of professional hunters seem stable in all five management-areas, while the number of leisure-hunters is going down. The reason for this could be the increasing price of renewing the hunter-license through the years 2010-2014. The professional hunter really needs to renew his hunter-license to keep on doing it for a living while the leisure-hunter does not really need it in the same way, but is hunting more or less for pleasure or as a supplement to everyday life, while having a normal day-to-day job.

The harvest-numbers as well as average catch per hunter for professional hunters from Nuuk went down from 20,8 in
2010 to 14,7 in 2014 and for Sisimiut they went down from 14,9 in 2010 to 11,0 in 2014 . This could indicate that the numbers of caribous in general are going down, but could also indicate that the competition from leisure-hunters is getting harder and the caribous are moving further up in the land. The leisure-hunters' harvest-numbers indicate that the latter could be the case - especially in Nuuk where the average catch per leisure-hunter went up from 1,1 in 2010 to 3,6 in 2014. However, only new surveys can tell for sure if the numbers of caribous actually are going down.

The harvest-numbers for professional hunters from Maniitsoq went down from 1214 in 2010 to 884 in 2012, but went up again to 1378 in 2014 . The low numbers -884 in 2012 and 919 in 2013 - could indicate some bad years in terms of caribou-hunting and the same tendency is obvious for the leisure-hunters. Bad years occur from time to time 
primarily due to weather-conditions.

Trophy-hunting on muskoxen is mainly concentrated in Kangerlussuaq where 9 organizers harvest a total of 200 muskoxen a year and in Ivittuut where 4 organizers harvest a total 80 muskoxen a year.

\subsection{The Lack of New Surveys on Caribou in Greenland}

Greenland has a number of international obligations mainly concerning marine mammals and therefore focus is mainly on marine mammals and not so much on terrestrial mammals such as the caribou - and on top of that fishery is also very important in Greenland. Therefore new surveys on caribous haven't been carried out since 2010 and 2012 meaning that there hasn't been basis for any biological advice on hunting the caribou during the last few years.

Caribou management in Greenland without any biological advice is the main challenge these years and all kinds of knowledge from the hunters has to be included as well as all the information gathered from the licenses and reports from the years catch mentioned earlier. The fat or lack of fat on each caribou being caught gives you an idea of how the conditions are in that particular part of that particular hunting-region and therefore information from the licenses is very important given the current situation without any biological advice. The harvest-numbers also mentioned before is also very important and provides information on the number of caribous out there from year to year and whether the numbers are going up or down.

According to the Executive Order management without any biological advice has to be carried out following the precautionary principle. This means that certain restrictions have been introduced mainly concerning leisure-hunting and until now mainly in the management-area called Nuuk, where the number of leisure-hunters exceeds the numbers in the other management-areas and the number of caribous isn't that high anymore.

\subsection{Conclusions}

Hunting the caribou in Greenland is mainly bound by tradition, where knowledge and skills are passed on through the generations from father to son and so onwards. The number of professional hunters and leisure-hunters vary from community to community and reflects the hunting-pressure to a certain extent and that is an important thing to bear in mind when you are talking management. Management used to be based mainly on biological advice provided by the Greenland Institute of Natural Resources, but during these last few years this has not been the case due to the lack of new surveys. The current situation in the four biggest caribou-regions in particular is to a certain degree unknown and therefore gathering information directly from the hunters, the licenses and in any other way is important when you're preparing and managing next year's hunting-periods and quotas.

\section{REFERENCES}

[1] Greenland Institute of Natural Resources Technical Report No. 78, 2011; revised 2012.

[2] Greenland Institute of Natural Resources Technical Report No. 98, 2016.

[3] Greenland Institute of Natural Resources Technical Report No. 46, 2002. 